\title{
The impact of levothyroxine sodium treatment on oxidative stress in Hashimoto's thyroiditis
}

\author{
Ihsan Ates ${ }^{1}$, Mustafa Altay ${ }^{2}$, Fatma Meric Yilmaz ${ }^{3}$, Canan Topcuoglu ${ }^{3}$, \\ Nisbet Yilmaz' ${ }^{1}$, Dilek Berker ${ }^{4}$ and Serdar Guler ${ }^{4,5}$ \\ ${ }^{1}$ Ankara Numune Training and Research Hospital, Department of Internal Medicine, Ankara, Turkey, \\ ${ }^{2}$ Kecioren Training and Research Hospital, Department of Internal Medicine, Ankara, Turkey, ${ }^{3}$ Ankara \\ Numune Training and Research Hospital, Department of Biochemistry, Ankara, Turkey, ${ }^{4}$ Ankara Numune \\ Training and Research Hospital, Department of Endocrinology, Ankara, Turkey and ${ }^{5}$ Hitit University \\ School of Medicine, Department of Endocrinology, Çorum, Turkey
}

Correspondence should be addressed to I Ates

Email

dr.ihsanates@hotmail.com

\begin{abstract}
Objective: Although several studies reported increased oxidative stress in Hashimoto's thyroiditis (HT), the effect of levothyroxine treatment on oxidative status is not studied extensively. Therefore, we conducted this study to investigate the effects of levothyroxine replacement on oxidative stress in HT.

Design and methods: Thirty-six patients recently diagnosed with HT-related hypothyroidism and 36 healthy controls were included in the study. Levothyroxine replacement was started to patients with hypothyroidism, and had been followed-up for 6 months.

Results: Mean basal serum total antioxidant status (TAS), total thiol, arylesterase, and paraoxonase 1 (PON1) levels were significantly lower, and serum total oxidant status (TOS) and oxidative stress index (OSI) were significantly higher in the patients with hypothyroid than the controls. In the hypothyroid group serum TAS, total thiol, arylesterase, and PON1 levels increased and serum TOS and OSI levels decreased significantly after levothyroxine treatment. Pretreatment serum TAS, total thiol, PON1, and arylesterase levels were positively correlated with free levothyroxine $\left(\mathrm{fT}_{4}\right)$ and negatively correlated with thyroid-stimulating hormone (TSH), antithyroid peroxidase (anti-TPO), and antithyroglobulin (anti-TG) levels. Also, pretreatment serum TOS and OSI levels were negatively correlated with $\mathrm{fT}_{4}$ levels and positively correlated with TSH, anti-TPO, and anti-TG. We have also found that the $\mathrm{fT}_{4}$ and anti-TPO levels are independent predictors of the oxidative stress parameters in stepwise multivariable linear regression analysis. Conclusion: This study suggests that levothyroxine replacement decreases oxidant status and increases antioxidant status following the 6 months of levothyroxine replacement in hypothyroidism that develops in accordance with the HT.

\section{Introduction}

Hashimoto's thyroiditis (HT), also known as chronic lymphocytic thyroiditis or autoimmune thyroiditis, is an organ-specific autoimmune disease characterized by intrathyroidal mononuclear cell infiltration and formation of antibodies against thyroid-specific antigens namely thyroid peroxidase and thyroglobulin (TG) (1). In this autoimmune thyroiditis, thyroid antibodies cause a decline
() 2016 European Society of Endocrinology Printed in Great Britain in the production of thyroid hormones by increasing the destruction of thyroid follicular cells. As the disease progresses, euthyroidism, subclinical hypothyroidism, and finally overt hypothyroidism are observed (2).

In the last few years, relationship between oxidative stress level and thyroid autoantibodies in HT has attracted a growing interest of researchers. Data from 
previous studies suggest that oxidative stress level may be increased due to chronic inflammation (3), deficient thyroid hormone levels (4), excessive autoimmune response, or excessive iodine intake (5) in HT. Reports of higher oxidative stress markers in hypothyroid patients with antithyroid peroxidase (anti-TPO) positivity compared with those without (anti-TPO (-)) (6) and increasing oxidative stress levels by the progression of HT from euthyroid to overt hypothyroid stage $(7,8,9)$ also supported previous data. In the light of these studies, it may be suggested that oxidative stress levels may have been increased in hypothyroid stage of HT, where thyroid hormone deficiency is at maximum levels (9). Furthermore, higher oxidative stress levels may also be expected in the existence of autoimmunity at hypothyroid stage (6).

Data are scarce in the literature regarding the effects of levothyroxine replacement on oxidative stress in hypothyroid phase of HT. In addition, these studies have investigated the effects of levothyroxine replacement on only some oxidant radicals and antioxidant enzymes $(10,11)$. No previous study had investigated the impact of levothyroxine replacement on overall oxidative state, which is defined by total oxidant status (TOS) and total antioxidant status (TAS). Therefore, we conducted this study to analyze the effects of levothyroxine replacement in hypothyroid stage of HT on overall oxidative stress, total thiol, paraoxonase 1 (PON1), and arylesterase.

\section{Patients and methods}

\section{Study population}

This study was performed prospectively in Internal Medicine and Endocrinology Departments of Ankara Numune Training and Research Hospital, Ankara, between April 2015 and August 2015. After iodination of table salt, Ankara has been one of the sufficient iodine supply regions of Turkey for a long time (12).

Thirty-six patients aged over 18 years, newly diagnosed with hypothyroidism due to HT, and never had been treated for this were included in the study. Age, BMI, and gender-matched 36 healthy volunteers served as the control group.

Patients with known diabetes mellitus, hypertension, other thyroid disease, acute/chronic kidney or liver disease, documented cardiovascular or cerebrovascular disease, malignancy, rheumatic disease, pregnancy, use of vitamin supplements, antioxidant drugs that alter oxidant status, history of smoking, or any amount of alcohol consumption were excluded from the study.
Diagnosis of HT is defined as thyroid antibody (antiTPO or anti-TG positivity in the serum and the presence of parenchyma heterogeneity in thyroid ultrasonography. Patients who had free thyroxine ( $\mathrm{fT}_{4}$ ) levels below normal range $(0.9-1.7 \mathrm{ng} / \mathrm{dL})$ and thyroid-stimulating hormone (TSH) levels above normal range $(0.5-4 \mu \mathrm{IU} / \mathrm{mL})$ are considered to have overt hypothyroidism. After the diagnosis, patients with hypothyroid were started on levothyroxine replacement, titrating the daily dose according to TSH level. Patients were informed about optimal use and storage of levothyroxine tablets.

BMI was calculated by dividing body weight with the square of height in meters $\left(\mathrm{BMI}=\mathrm{kg} / \mathrm{m}^{2}\right)$.

The study protocol was conducted in accordance with the Helsinki Declaration 2013 Brazil version and was approved by the Local Ethics Research Committee. All subjects provided written informed consent before participation in the study.

\section{Blood sample collection}

Venous serum samples were obtained from the patient group at baseline and 6 months after the initiation of levothyroxine treatment (euthyroid stage). Venous serum samples of healthy controls were obtained only once at the time they were included in the study. Five milliliter blood sample was obtained from each subject in the patient and control groups after $12 \mathrm{~h}$ of overnight fasting, between 0800 and $0900 \mathrm{~h}$ for the assessment of oxidative stress parameters. After the centrifugation for $10 \mathrm{~min}$ at $1500 \mathbf{g}$ serum samples were separated into Eppendorf tubes and stored at $-80^{\circ} \mathrm{C}$ until assay. All samples are defrosted and assayed once and simultaneously.

\section{Biochemical assays}

Total cholesterol, HDL-cholesterol, and triglyceride levels were measured by colorimetric enzymatic method using Hitachi Modular P800 (Roche Diagnostics) analyzer. LDLcholesterol was calculated by the method by Friedewald et al. (13). TSH, $\mathrm{fT}_{4}$, anti-TPO (normal range: $0-34 \mathrm{IU} / \mathrm{mL}$ ), and anti-TG (normal range: $0-115 \mathrm{IU} / \mathrm{mL}$ ) levels were measured by electroluminescence immunoassay method in Cobas E601 (Roche Diagnostics) analyzer.

\section{Oxidative stress parameters}

There are lots of molecules that reflect the oxidant and antioxidant status of the body. TAS and TOS reflect the 
general status of the oxidative stress in the body. Total thiol is an antioxidant that can react with free radicals in order to protect against tissue and cell damage, which is caused by reactive oxygen species. The arylesterase and PON1 are serum arylesterase enzymes that are closely bound to HDL-cholesterol, which protects LDL-cholesterol against oxidative damage. Oxidative stress index (OSI) is an indicative parameter of the degree of oxidative stress.

\section{Measurement of total antioxidant status}

Serum TAS levels were measured by colorimetric method using a commercially available kit (Rel Assay Diagnostics, Gaziantep, Turkey, REF No: RL0024, LOT No: JE 14048Og). The results were expressed in mmol Trolox Eq./L.

\section{Measurement of total oxidant status}

Serum TOS levels were measured by colorimetric method using a commercially available kit (Rel Assay Diagnostics, Gaziantep, Turkey, REF No: RL0017, LOT No: JE 14042A). The results were expressed in $\mu \mathrm{mol}$ hydrogen peroxide $\left(\mathrm{H}_{2} \mathrm{O}_{2}\right)$ Eq./L.

\section{Measurement of total thiol}

Serum total thiol levels were measured by colorimetric method using a commercially available kit (Rel Assay Diagnostics, Gaziantep, Turkey, REF No: RL0178, LOT No: AL 13011TL). The results were expressed in $\mathrm{mmol} / \mathrm{L}$.

\section{Measurement of PON1}

Serum PON1 levels were measured by colorimetric method using a commercially available kit (Rel Assay Diagnostics, Gaziantep, Turkey, REF No: RL0031, LOT No: JE14028P). The results were expressed in U/L.

\section{Measurement of arylesterase}

Serum arylesterase levels were measured by colorimetric method using a commercially available kit (Rel Assay Diagnostics, Gaziantep, Turkey, REF No: RL0055, LOT No: JR13017AR). The results were expressed in U/L.

\section{Oxidative stress index}

The OSI value was calculated according to the following formula: OSI (arbitrary unit) $=\mathrm{TOS}\left(\mu \mathrm{mol} \mathrm{H}_{2} \mathrm{O}_{2}\right.$ Eq./L)/TAS (mmol Trolox Eq./L) (14).

\section{Thyroid ultrasonography}

Thyroid ultrasonography was performed by one radiologist using Logiq 7 (GE Health Medical) ultrasound machine with a $7.5 \mathrm{MHz}$ probe. Thyroiditis was diagnosed by the presence of heterogeneity in thyroid parenchyma.

\section{Statistical analysis}

Statistical analysis was carried out using SPSS for Windows version 20. Normal distribution was evaluated by Kolmogorov-Smirnov test. Numerical parameters were presented as mean \pm s.D. or median (min-max). Categorical variables were expressed as numbers and percentage. Comparison between the control patients and pretreatment patients with hypothyroidism or pre- and post-treatment patients with hypothyroidism was done by Student's t-test or Mann-Whitney U test. Changes in the laboratory findings of patients with hypothyroidism before and after treatment were analyzed using paired-samples $t$-test. The stepwise linear regression analysis was used for the detection of risk factors affecting oxidative stress levels. The stepwise logistic regression analysis was used

Table 1 Comparison of characteristics and laboratory findings of pretreatment patients with hypothyroidism (HT) and control group. Numerical variables were expressed as mean \pm s.d. or median (min-max).

\begin{tabular}{|c|c|c|c|}
\hline Variables & $\begin{array}{l}\text { HT pretreatment } \\
n=(36)\end{array}$ & $\begin{array}{c}\text { Control } \\
n=(36)\end{array}$ & $P$-value \\
\hline $\begin{array}{l}\text { Gender, male, } \\
n(\%)\end{array}$ & $9(25.0)$ & $9(25.0)$ & 0.999 \\
\hline Age (years) & $41.4 \pm 13.9$ & $41.3 \pm 8.8$ & 0.978 \\
\hline BMI $\left(\mathrm{kg} / \mathrm{m}^{2}\right)$ & $28.4 \pm 5.9$ & $28.1 \pm 4.1$ & 0.903 \\
\hline TSH $(\mu \mathrm{IU} / \mathrm{mL})$ & $12.9(6.6-100)$ & $1.7(0.5-3.5)$ & $<0.001$ * \\
\hline $\mathrm{fT}_{4}(\mathrm{ng} / \mathrm{dL})$ & $0.7(0.1-0.8)$ & $1.1(0.9-1.5)$ & $<0.001$ * \\
\hline Anti-TG (IU/mL) & $325.4(10-4000)$ & $11.5(4-95.2)$ & $<0.001 *$ \\
\hline Anti-TPO (IU/mL) & $226.2(9-1000)$ & $8.2(4-20.6)$ & $<0.001$ * \\
\hline $\begin{array}{l}\text { Total cholesterol } \\
\text { (mg/dL) }\end{array}$ & $217.8 \pm 46.8$ & $188.8 \pm 29.9$ & $0.003 *$ \\
\hline $\begin{array}{l}\text { Triglyceride } \\
\text { (mg/dL) }\end{array}$ & $109(49-346)$ & $100(39-280)$ & 0.999 \\
\hline LDL (mg/dL) & $105.2 \pm 21.6$ & $100.7 \pm 24.2$ & 0.408 \\
\hline HDL (mg/dL) & $48.3 \pm 12.1$ & $54.4 \pm 15.5$ & 0.223 \\
\hline $\begin{array}{l}\text { TAS (mmol } \\
\text { Trolox Eq./L) }\end{array}$ & $1.5 \pm 0.3$ & $1.7 \pm 0.2$ & $<0.001$ * \\
\hline $\begin{array}{l}\text { TOS }\left(\mu \mathrm{mol} \mathrm{H}_{2} \mathrm{O}_{2}\right. \\
\text { Eq./L) }\end{array}$ & $6.3 \pm 1.8$ & $4.8 \pm 1.6$ & $0.036 *$ \\
\hline $\begin{array}{l}\text { OSI (arbitrary } \\
\text { unit) }\end{array}$ & $4.4 \pm 0.9$ & $2.8 \pm 0.9$ & $0.002 *$ \\
\hline $\begin{array}{l}\text { Total thiol } \\
(\mathrm{mmol} / \mathrm{L})\end{array}$ & $440.4 \pm 87.9$ & $490.3 \pm 74.6$ & $0.039 *$ \\
\hline Arylesterase (U/L) & $1098.6 \pm 156.6$ & $1323.1 \pm 211.2$ & $<0.001$ * \\
\hline PON1 (U/L) & $432.8 \pm 62.9$ & $466.0 \pm 31.4$ & 0.020 * \\
\hline
\end{tabular}


Table 2 Comparison of laboratory findings of pre- and post-treatment patients with hypothyroidism. Numerical variables were expressed as mean \pm s.d. or median (min-max).

\begin{tabular}{|c|c|c|c|}
\hline \multirow[b]{2}{*}{ Variables } & \multicolumn{2}{|c|}{ Hypothyroidism } & \multirow[b]{2}{*}{$P$-value } \\
\hline & $\begin{array}{l}\text { Pretreatment } \\
\qquad n=(36)\end{array}$ & $\begin{array}{l}\text { Post-treatment } \\
\qquad n=(36)\end{array}$ & \\
\hline TSH $(\mu \mathrm{IU} / \mathrm{mL})$ & $12.9(6.6-100)$ & $2.3(0.4-4.4)$ & $<0.001 *$ \\
\hline $\mathrm{fT}_{4}(\mathrm{ng} / \mathrm{dL})$ & $0.7(0.1-0.8)$ & $1.1(0.9-1.7)$ & $<0.001$ * \\
\hline $\begin{array}{l}\text { Anti-TG } \\
(\text { IU/mL) }\end{array}$ & $325.4(10-4000)$ & $126.8(20-656)$ & $<0.001$ * \\
\hline $\begin{array}{c}\text { Anti-TPO } \\
\text { (IU/mL) }\end{array}$ & $226.2(9-1000)$ & $105(1.7-350.0)$ & $<0.001$ * \\
\hline $\begin{array}{l}\text { Total } \\
\text { cholesterol } \\
\text { (mg/dL) }\end{array}$ & $217.8 \pm 46.8$ & $170.8 \pm 30.2$ & $<0.001$ * \\
\hline $\begin{array}{l}\text { Triglyceride } \\
\text { (mg/dL) }\end{array}$ & $109(49-346)$ & $108(33-356)$ & 0.999 \\
\hline LDL (mg/dL) & $105.2 \pm 21.6$ & $99.3 \pm 25.1$ & 0.289 \\
\hline HDL (mg/dL) & $48.3 \pm 12.1$ & $51.6 \pm 15.8$ & 0.885 \\
\hline $\begin{array}{l}\text { TAS (mmol } \\
\text { Trolox Eq./L) }\end{array}$ & $1.5 \pm 0.3$ & $1.7 \pm 0.2$ & $<0.001$ * \\
\hline $\begin{array}{l}\mathrm{TOS}(\mu \mathrm{mol} \\
\mathrm{H}_{2} \mathrm{O}_{2} \text { Eq./L) }\end{array}$ & $6.3 \pm 1.8$ & $4.4 \pm 1.3$ & $0.007 *$ \\
\hline $\begin{array}{l}\text { OSI (arbitrary } \\
\text { unit) }\end{array}$ & $4.4 \pm 0.9$ & $2.6 \pm 0.7$ & $<0.001$ * \\
\hline $\begin{array}{l}\text { Total thiol } \\
(\mathrm{mmol} / \mathrm{L})\end{array}$ & $440.4 \pm 87.9$ & $496.0 \pm 103.3$ & $0.028 *$ \\
\hline $\begin{array}{l}\text { Arylesterase } \\
(\mathrm{U} / \mathrm{L})\end{array}$ & $1098.6 \pm 156.6$ & $1247.5 \pm 257.9$ & $0.011 *$ \\
\hline PON1 (U/L) & $432.8 \pm 62.9$ & $470.8 \pm 53.2$ & $0.006^{*}$ \\
\hline
\end{tabular}

for the detection of risk factors affecting hypothyroidism. A $P$ value of $<0.05$ was considered to be significant for statistical analyses.

\section{Results}

Table 1 summarizes the characteristics and laboratory findings of pretreatment patients with hypothyroidism and control group. Seventy-two subjects, 36 patients with hypothyroidism (9 males, 27 females; mean age: $41.4 \pm 13.9$ years), and 36 healthy controls (9 males, 27 females; mean age: $41.3 \pm 8.8$ years) were included in the study.

The two groups were similar with regard to sex, age, and BMI $(P>0.05)$. Basal TSH $(P<0.001)$, anti-TPO $(P<0.001)$, anti-TG $(P<0.001)$, and total cholesterol levels $(P=0.003)$ were significantly higher and $\mathrm{fT}_{4}$ level $(P<0.001)$ was significantly lower in pretreatment hypothyroid group than the control group.

Basal TOS and OSI ratio were significantly higher ( $P=0.036$ and $P=0.002$, respectively) and basal arylesterase, TAS, total thiol, and PON1 levels were significantly lower $(P<0.001, P<0.001, P=0.039$, and $P=0.020$, respectively) than the healthy controls.

\section{Effect of levothyroxine treatment}

Table 2 summarizes laboratory findings of pre- and posttreatment patients with hypothyroidism. All patients were found to have normalized $\mathrm{TSH}$ and $\mathrm{fT}_{4}$ levels after 6 months of levothyroxine replacement. Posttreatment median anti-TPO and anti-TG levels were lower compared with pretreatment levels $\left(P_{\text {pre-post }}<0.001\right)$. Mean total cholesterol level decreased significantly after the treatment $\left(P_{\text {pre-post }}<0.001\right)$. There was no statistically significant difference between groups regarding other lipid parameters $(P>0.05)$. With levothyroxine treatment mean TOS and OSI ratio significantly decreased $(6.3 \pm 1.8$ vs $4.4 \pm 1.3, P=0.007$ and $4.4 \pm 0.9$ vs $2.6 \pm 0.7, P<0.001$, respectively). Levothyroxine treatment resulted in significant increases in arylesterase (from $1098.6 \pm 156.6$ to $1247.5 \pm 257.9, P=0.011$ ), TAS (from $1.5 \pm 0.3$ to $1.7 \pm 0.2$, $P<0.001$ ), total thiol (from $440.4 \pm 87.9$ to $496.0 \pm 103.3$, $P=0.028$ ), and PON1 (from $432.8 \pm 62.9$ to $470.8 \pm 53.2$, $P=0.006)$ levels. Mean or median post-treatment levels of all these parameters were similar between the patients and the controls $(P>0.05$ for all $)$.

In the pretreatment patients with HT, the correlation analysis between oxidative stress parameters and other laboratory parameters is shown in Table 3. Pretreatment TAS $((r=0.575, P=0.001), \quad(r=-0.344, P=0.028), \quad(r=-0.546$, $P=0.003),(r=-0.503, P=0.001)$, respectively), total thiol $((r=0.470, P=0.010), \quad(r=-0.375, P=0.018), \quad(r=-0.465$, $P=0.003), \quad(r=-0.394, \quad P=0.007), \quad$ respectively $), \quad P O N 1$ $((r=0.510, P=0.001), \quad(r=-0.340, P=0.022), \quad(r=-0.478$, $P=0.004),(r=-0.390, P=0.008)$, respectively), and arylesterase levels $((r=0.520, P=0.005),(r=-0.388, P=0.009)$, ( $r=-0.503, P=0.003),(r=-0.418, P=0.009)$, respectively) were found to be positively correlated with $\mathrm{fT}_{4}$ and negatively correlated with TSH, anti-TPO, and anti-TG levels. Also, pretreatment TOS $((r=-0.539, P=0.001),(r=0.350$, $P=0.002), \quad(r=0.467, \quad P=0.004), \quad(r=0.406, \quad P=0.006)$, respectively) and OSI $((r=-0.554, P=0.001),(r=0.377$, $P=0.017), \quad(r=0.486, \quad P=0.001), \quad(r=0.446, \quad P=0.007)$, respectively) levels were negatively correlated with $\mathrm{fT}_{4}$ levels and positively correlated with TSH, anti-TPO, and anti-TG.

In stepwise multivariable linear regression analysis, $\mathrm{fT}_{4}$ and anti-TPO levels were found to be independent predictors of the OSI, TAS, TOS, total thiol, PON1, and arylesterase before the treatment. In stepwise multivariable logistic regression analysis, TSH, anti-TPO, 
Table 3 Relationship between the oxidative stress parameters levels and other laboratory parameters before the treatment in patients with HT.

\begin{tabular}{|c|c|c|c|c|c|c|}
\hline \multirow[b]{2}{*}{ Variables } & \multicolumn{2}{|c|}{ TAS } & \multicolumn{2}{|c|}{ TOS } & \multicolumn{2}{|c|}{ Total thiol } \\
\hline & $r$ & $P$-value & $r$ & $P$-value & $r$ & $P$-value \\
\hline TSH & -0.344 & $0.028 *$ & 0.350 & $0.002 *$ & -0.375 & $0.018 *$ \\
\hline $\mathrm{fT}_{4}$ & 0.575 & $0.001 *$ & -0.539 & 0.001 * & 0.470 & 0.010 * \\
\hline Anti-TPO & -0.546 & $0.003 *$ & 0.467 & $0.004 *$ & -0.465 & $0.003 *$ \\
\hline Anti-TG & -0.503 & 0.001 * & 0.406 & 0.006 * & -0.394 & 0.007 * \\
\hline
\end{tabular}

\begin{tabular}{|c|c|}
\hline \multicolumn{2}{|c|}{ Arylesterase } \\
\hline$r$ & $P$-value \\
\hline-0.388 & $0.009 *$ \\
\hline 0.520 & $0.005^{*}$ \\
\hline-0.503 & $0.003 *$ \\
\hline-0.418 & 0.009 * \\
\hline
\end{tabular}

\begin{tabular}{|c|c|}
\hline \multicolumn{2}{|c|}{ PON1 } \\
\hline$r$ & $P$-value \\
\hline-0.340 & $0.022 *$ \\
\hline 0.510 & 0.001 * \\
\hline-0.478 & 0.004 * \\
\hline-0.390 & $0.008^{*}$ \\
\hline
\end{tabular}

\begin{tabular}{|c|c|}
\hline \multicolumn{2}{|c|}{ OSI } \\
\hline$r$ & $P$-value \\
\hline 0.377 & $0.017^{*}$ \\
\hline-0.554 & $0.001 *$ \\
\hline 0.486 & 0.001 * \\
\hline 0.446 & 0.007 * \\
\hline
\end{tabular}

OSI, and arylesterase levels were found to be independent predictors of hypothyroidism (Table 4).

\section{Discussion}

To our knowledge, this is the first study to demonstrate increased TAS, total thiol, PON1, and arylesterase and decreased TOS and OSI levels following levothyroxine replacement in patients with HT.

In our study, we found that TOS and OSI levels were higher, while TAS levels were lower in patients with HT before levothyroxine replacement compared with controls. Oxidative stress develops as a result of insufficiency of antioxidant mechanisms against increased oxidant radicals. Higher oxidative stress levels in patients with hypothyroid due to HT compared with those unrelated to HT and healthy controls were previously demonstrated by various studies $(6,10,15,16)$. For instance, Nanda et al. (6) reported higher oxidative stress levels in anti-TPO (+) patients with hypothyroid compared with anti-TPO (-) patients with hypothyroid. Three different studies also had reported higher oxidative stress levels in HT compared with healthy controls, supporting our data $(4,9,10,16)$.

High level of oxidative stress in HT might be due to a variety of reason. The most plausible reason would be chronic inflammation causing high oxidative stress. It is thought that $\mathrm{T}$ and $\mathrm{B}$ lymphocytes play an active role in the pathogenesis of HT, and may cause an increase in reactive oxygen radicals by activating NADPH oxidase (NOX) enzyme $(3,17)$. Indeed, this had been proven in wildtype mice by the demonstration of increase in $\mathrm{H}_{2} \mathrm{O}_{2}$ and superoxide anions in $\mathrm{T}$ cells via the stimulation of $\mathrm{T}$ cell receptors by antigens or mitogens (18). Another reason of high oxidative stress in HT might be deficiency of thyroid hormones (15). Thyroid hormones are thought to contribute to free oxygen radical cleaning by increasing nonenzymatic antioxidant molecules (19) which affect antioxidant enzyme levels such as superoxide dismutase, catalase, and glutathione peroxidase (20), and cause the stimulation of mitochondrial uncoupling proteins which are nonenzymatic antioxidant molecules (21). Lastly, high oxidative stress in HT might be due to excessive iodine intake and autoimmune response. $\mathrm{H}_{2} \mathrm{O}_{2}$ which is an oxidant radical is needed for the oxidation of iodide during thyroid hormone synthesis in thyroid epithelial cells. High iodine intake causes excessive $\mathrm{H}_{2} \mathrm{O}_{2}$ production. In this case, oxidant radicals start to rise in the body (22). Excessive autoimmune response is also thought to increase oxidative stress by exaggerating inflammation or causing a decrease in thyroid hormone synthesis by increasing tissue injury.

In the light of these data, we have thought to investigate the effect of levothyroxine replacement on oxidative stress in hypothyroid patients with HT. There are only a few studies in the literature to demonstrate impacts of levothyroxine replacement on oxidant and antioxidant molecules. Baskol et al. (10) reported a decrease in malondialdehyde (MDA) and increase in PON and superoxide dismutase levels after 6 months of levothyroxine replacement. Similarly, a decrease in MDA levels after 2 months of levothyroxine replacement was demonstrated by Erdamar et al. (23). However, both studies have only investigated the effects of levothyroxine replacement on oxidant and antioxidant molecules, and had not evaluated the overall oxidative stress in the body.

In our study, post-treatment TAS, total thiol, PON1, and arylesterase levels were higher and TOS and OSI levels were lower compared with pretreatment levels. Increase in TAS levels and decrease in TOS levels after levothyroxine replacement can be explained by a few mechanisms. One explanation would be levothyroxine replacement causing a decrease in chronic inflammation, which plays an important role in HT. Previous studies showed decreased TNF- $\alpha$, interleukin (IL)- $1 \beta$, IL- 6 , and monocyte chemoattractant protein-1 levels in euthyroid group (24), decreased intercellular adhesion molecule-1 levels in subclinical hypothyroid group (25), and decreased C-reactive protein levels in another subclinical hypothyroid group after levothyroxine replacement (26). In addition, levothyroxine replacement has also been shown to decrease 
Table 4 The determination of independent predictors of oxidative stress parameters and hypothyroidism with stepwise regression analysis.

\begin{tabular}{|c|c|c|c|c|c|c|c|}
\hline & & & & & & & \\
\hline & $\beta \pm$ S.E.M. & OR & $R^{2}$ & $P$-value & Lower & Upper & $P$-value \\
\hline Stepwise linear & del $^{*}$ & & & & & & \\
\hline TAS & & & 0.596 & $<0.001$ & & & \\
\hline fT4 & $0.565 \pm 0.076$ & & & & 0.325 & 0.805 & $0.002 *$ \\
\hline Anti-TPO & $-0.471 \pm 0.097$ & & & & -0.721 & -0.221 & $0.005^{*}$ \\
\hline TOS & & & 0.649 & 0.001 & & & \\
\hline $\mathrm{fT} 4$ & $-0.881 \pm 0.100$ & & & & -1.101 & -0.660 & $<0.001$ * \\
\hline Anti-TPO & $0.782 \pm 0.245$ & & & & 0.244 & 1.321 & 0.008 * \\
\hline Total thiol & & & 0.641 & 0.002 & & & \\
\hline fT4 & $0.890 \pm 0.287$ & & & & 0.287 & 1.494 & 0.006 * \\
\hline Anti-TPO & $-0.719 \pm 0.223$ & & & & -1.186 & -0.251 & $0.005^{*}$ \\
\hline Arylesterase & & & 0.627 & 0.001 & & & \\
\hline fT4 & $0.992 \pm 0.322$ & & & & 0.319 & 1.665 & 0.006 * \\
\hline Anti-TPO & $-0.885 \pm 0.169$ & & & & -1.239 & -0.531 & 0.001 * \\
\hline PON1 & & & & & & & \\
\hline fT4 & $0.623 \pm 0.168$ & & 0.594 & 0.001 & 0.271 & 0.974 & 0.001 * \\
\hline Anti-TPO & $-0.409 \pm 0.061$ & & & & -2.006 & -0.294 & 0.011 * \\
\hline OSI & & & & & & & \\
\hline $\mathrm{fT} 4$ & $-0.780 \pm 0.283$ & & 0.643 & $<0.001$ & -1.380 & -0.185 & $0.013^{*}$ \\
\hline Anti-TPO & $0.699 \pm 0.249$ & & & & 0.177 & 1.220 & 0.011 * \\
\hline Stepwise logisti & odel $^{+}$ & & & & & & \\
\hline Hypothyroidisr & & & & & & & \\
\hline TSH & & 9.190 & 0.857 & $<0.001$ & 1.460 & 37.857 & $0.018^{*}$ \\
\hline Anti-TPO & & 1.320 & & & 1.051 & 1.658 & 0.017 * \\
\hline OSI & & 2.660 & & & 1.429 & 4.951 & $0.002 *$ \\
\hline Arylesterase & & 0.990 & & & 0.984 & 0.998 & $0.003 *$ \\
\hline
\end{tabular}

${ }^{*} P<0.05$ statistical significance. ${ }^{\ddagger}$ Stepwise linear regression model was done using age, sex, $\mathrm{BMI}, \mathrm{TSH}_{1} \mathrm{fT}_{4}$, anti-TG, anti-TPO, total cholesterol, triglyceride, $\mathrm{LDL}$, and $\mathrm{HDL}$ as risk factors. Before regression analysis, logarithmical transformation was performed on $\mathrm{TSH} \mathrm{fT}_{4}$, anti-TG, and anti-TPO. ${ }^{+} \mathrm{Stepwise}$ logistic regression model was done using $\mathrm{TSH}_{1} \mathrm{fT}_{4}$, anti-TG, anti-TPO, total cholesterol, TAS, TOS, OSI, total thiol, arylesterase, and PON1 as risk factors.

$\beta$, unstandardized coefficients.

lymphocyte infiltration in rats and cats with $\mathrm{HT}(27,28)$. Increase of reactive oxygen molecules by NOX enzyme during chronic inflammation was previously reported $(3,17)$. In our study, since no inflammation marker was tested, contribution of decreased chronic inflammation to decreased oxidative stress cannot be evaluated. However, decreased post-treatment thyroid antibody levels in our study may indirectly indicate a decrease in chronic inflammation.

The second factor affecting decreased oxidative stress in our study may be increase in levels of thyroid hormones. Thyroid hormones had been shown to remove free oxygen radicals by increasing levels of enzymatic and nonenzymatic antioxidant molecules, thereby decreasing the oxidative stress $(19,20,21)$. Baskol et al. reported increase in levels of superoxide dismutase enzyme, which plays a role in removal of oxygen radicals, after levothyroxine replacement compared with superoxide dismutase enzyme level before treatment. Supporting these data, we have shown an increase in the levels of antioxidant enzymes, namely PON1 and arylesterase, compared with pretreatment levels. Moreover, we have also demonstrated that increase in $\mathrm{fT}_{4}$ levels is an independent factor for the increase in TAS and decrease in TOS and OSI levels. In summary, our results suggest that thyroid replacement therapy has a decreasing effect on oxidative stress.

Furthermore, we have also determined that antiTPO level is an independent risk factor for oxidative stress. Several previous studies reported decreased thyroid antibody levels following levothyroxine replacement (29, $30,31)$. Increased TSH levels had been shown to increase autoantibody levels by stimulating lymphocytes (29). In addition, high levels of TSH may also increase thyroid antigen levels, therefore, antibody levels might increase via an indirect effect (32). After levothyroxine replacement, when TSH levels decrease, antibody levels also decrease due to a decline in both lymphocyte induction rate and formation of thyroid-specific antigens. Thus, a decrease in autoantibody levels may be an indirect indicator of decreased chronic inflammation.

In this study, we have found that the $\mathrm{fT}_{4}$ and antiTPO levels are independent predictors of the oxidative stress parameters in stepwise multivariable linear 
regression analysis. In the case of thyroid hormone deficiency, glutathione peroxidase (GPX), which is responsible for the removal of oxidant radicals by a reaction with thiol compounds, starts to increase as a protective mechanism. Increased GPX decreases total thiol reserves by causing oxidation of thiol compounds (5). Glutathione reductase (GR) is an enzyme that is responsible for the reduction of oxidated thiol compounds. It has been reported in a study on rats that GR levels decreased at the 30th day, and GPX levels increased at the 90th day of levothyroxine replacement (33). In the light of these data, we may assume that decreased total thiol levels in our study may be due to decreased GPX and increased GR levels.

Post-treatment increase of arylesterase enzyme levels in our study may be due to both decreased oxidant radicals and decrease of total cholesterol levels following therapy. An increase in oxidant radicals (10) and cholesterol levels (34) had been previously reported to decrease PON levels.

The major limitations of this study include the lack of an inflammatory marker and lack of urine iodine analysis to confirm excessive intake of iodine, small sample size, and the cross-sectional nature of the study.

In conclusion, our data suggest that levothyroxine replacement decreases oxidant status and increases antioxidant status. This condition urges us to consider that lack of thyroid hormone may be effective in increasing the oxidative stress of patients with hypothyroid. In the logistic regression analysis, determination of OSI as an independent risk factor for the hypothyroidism also supports this fact. Further studies are required in order to justify whether the oxidative stress is a cause or result of hypothyroidism.

\section{Declaration of interest}

The authors declare that there is no conflict of interest that could be perceived as prejudicing the impartiality of the research reported.

\section{Funding}

This study did not receive any specific grant from any funding agency in the public, commercial, or nonprofit sectors.

\section{Author contribution statement}

I A, M A, and S G: conception, design, and manuscript writing. F M Y and C $\mathrm{T}$ : laboratory analysis. All authors contributed to data collection and data interpretation, and approved the manuscript.

\section{References}

1 Dayan CM \& Daniels GH. Chronic autoimmune thyroiditis. New England Journal of Medicine 1996335 99-107. (doi:10.1056/ NEJM199607113350206)
2 Pearce EN, Farwell AP \& Braverman LE. Thyroiditis. New England Journal of Medicine 2003348 2646-2655.

3 Jackson SH, Devadas S, Kwon J, Pinto LA \& Williams MS. T cells express a phagocyte-type NADPH oxidase that is activated after T cell receptor stimulation. Nature Immunology 20045 818-827. (doi:10.1038/ni1096)

4 Baser H, Can U, Baser S, Yerlikaya FH, Aslan U \& Hidayetoglu BT. Assesment of oxidative status and its association with thyroid autoantibodies in patients with euthyroid autoimmune thyroiditis. Endocrine 201548 916-923. (doi:10.1007/s12020014-0399-3)

5 Rostami R, Aghasi MR, Mohammadi A \& Nourooz-Zadeh J. Enhanced oxidative stress in Hashimoto's thyroiditis: inter-relationships to biomarkers of thyroid function. Clinical Biochemistry 201346 308-312. (doi:10.1016/j.clinbiochem.2012.11.021)

6 Nanda N, Bobby Z \& Hamide A. Oxidative stress in anti thyroperoxidase antibody positive hypothyroid patients. Asian Journal of Biochemistry 20127 54-58. (doi:10.3923/ajb.2012.54.58)

7 Ozturk U, Vural P, Ozderya A, Karadag B, Dogru-Abbasoglu S \& Uysal M. Oxidative stress parameters in serum and low density lipoproteins of Hashimoto's thyroiditis patients with subclinical and overt hypothyroidism. International Immunopharmacology 201214 349-352. (doi:10.1016/j.intimp.2012.08.010)

8 Reddy VS, Gouroju S, Suchitra MM, Suresh V, Sachan A, Srinivasa Rao PV \& Bitla AR. Antioxidant defense in overt and subclinical hypothyroidism. Hormone and Metabolic Research 201345 754-758. (doi:10.1055/s-00000025)

9 Ates I, Yilmaz FM, Altay M, Yilmaz N, Berker D \& Guler S. The relationship between oxidative stress and autoimmunity in Hashimoto's thyroiditis. European Journal of Endocrinology 2015173 791-799. (doi:10.1530/EJE-15-0617)

10 Baskol G, Atmaca H, Tanriverdi F, Baskol M, Kocer D \& Bayram F. Oxidative stress and enzymatic antioxidant status in patients with hypothyroidism before and after treatment. Experimental and Clinical Endocrinology \& Diabetes 2007115 522-526.

11 Azizi F, Raiszadeh F, Solati M, Etemadi A, Rahmani M \& Arabi M. Serum paraoxonase 1 activity is decreased in thyroid dysfunction. Journal of Endocrinological Investigation 200326 703-709. (doi:10.1007/BF03347350)

12 Erdogan MF, Agbaht K, Altunsu T, Ozbas S, Yucesan F, Tezel B, Sargin C, Ilbeg I, Artik N, Kose R et al. Current iodine status in Turkey. Journal of Endocrinological Investigation 200932 617-622. (doi:10.1007/BF03346519)

13 Friedewald WT, Levy RI \& Fredrickson DS. Estimation of the concentration of low-density lipoprotein cholesterol in plasma, without use of the preparative ultracentrifuge. Clinical Chemistry 1972 18 499-502.

14 Ulas T, Buyukhatipoglu H, Kirhan I, Dal MS, Ulas S, Demir ME, Eren MA, Ucar M, Hazar A, Kurkcuoglu IC et al. Evaluation of oxidative stress parameters and metabolic activities of nurses working day and night shifts. Revista da Escola de Enfermagem da USP 201347 471-476.

15 Baser H, Can U, Baser S, Yerlikaya FH, Aslan U \& Hidayetoglu BT. Assesment of oxidative status and its association with thyroid autoantibodies in patients with euthyroid autoimmune thyroiditis. Endocrine 201448 916-923.

16 Wang D, Feng JF, Zeng P, Yang YH, Luo J \& Yang YW. Total oxidant/ antioxidant status in sera of patients with thyroid cancers. EndocrineRelated Cancer 201118 773-782. (doi:10.1530/ERC-11-0230)

17 Bedard K \& Krause KH. The NOX family of ROS-generating NADPH oxidases: physiology and pathophysiology. Physiological Reviews 2007 87 245-313. (doi:10.1152/physrev.00044.2005)

18 Devadas S, Zaritskaya L, Rhee SG, Oberley L \& Williams MS. Discrete generation of superoxide and hydrogen peroxide by $\mathrm{T}$ cell receptor stimulation: selective regulation of mitogen-activated protein kinase 
activation and fas ligand expression. Journal of Experimental Medicine 2002195 59-70. (doi:10.1084/jem.20010659)

19 Venditti P, Balestrieri M, Di Meo S \& De Leo T. Effect of thyroid state on lipid peroxidation, antioxidant defences, and susceptibility to oxidative stress in rat tissues. Journal of Endocrinology $1997 \mathbf{1 5 5}$ 151-157. (doi:10.1677/joe.0.1550151)

20 Fernandez V, Llesuy S, Solari L, Kipreos K, Videla LA \& Boveris A. Chemiluminescent and respiratory responses related to thyroid hormone-induced liver oxidative stress. Free Radical Research Communications 19885 77-84. (doi:10.3109/10715768809066914)

21 Rousset S, Alves-Guerra MC, Mozo J, Miroux B, Cassard-Doulcier AM, Bouillaud F \& Ricquier D. The biology of mitochondrial uncoupling proteins. Diabetes 200453 (Supplement 1) S130-S135.

22 Burek CL \& Rose NR. Autoimmune thyroiditis and ROS. Autoimmunity Reviews 20087 530-537. (doi:10.1016/j.autrev.2008.04.006)

23 Erdamar H, Demirci H, Yaman H, Erbil MK, Yakar T, Sancak B, Elbeg S, Biberoglu G \& Yetkin I. The effect of hypothyroidism, hyperthyroidism, and their treatment on parameters of oxidative stress and antioxidant status. Clinical Chemistry and Laboratory Medicine 200846 1004-1010.

24 Krysiak R \& Okopien B. The effect of levothyroxine and selenomethionine on lymphocyte and monocyte cytokine release in women with Hashimoto's thyroiditis. Journal of Clinical Endocrinology \& Metabolism 201196 2206-2215.

25 Kowalska I, Borawski J, Nikolajuk A, Budlewski T, Otziomek E, Gorska M \& Straczkowski M. Insulin sensitivity, plasma adiponectin and sICAM-1 concentrations in patients with subclinical hypothyroidism: response to levothyroxine therapy. Endocrine 2011 40 95-101. (doi:10.1007/s12020-011-9446-5)

26 Velija-Asimi Z \& Karamehic J. The effects of treatment of subclinical hypothyroidism on metabolic control and hyperinsulinemia. Medical Archives 200761 20-21.
27 Reinhardt W, Paul TL, Allen EM, Alex S, Yang YN, Appel MC \& Braverman LE. Effect of L-thyroxine administration on the incidence of iodine induced and spontaneous lymphocytic thyroiditis in the BB/Wor rat. Endocrinology 1988122 1179-1181.

28 Schumm-Draeger PM \& Fortmeyer HP. Autoimmune thyroiditis - spontaneous disease models - cat. Experimental and Clinical Endocrinology \& Diabetes 1996104 (Supplement 3) 12-13; discussion 14-16.

29 Romaldini JH, Biancalana MM, Figueiredo DI, Farah CS \& Mathias PC. Effect of L-thyroxine administration on antithyroid antibody levels, lipid profile, and thyroid volume in patients with Hashimoto's thyroiditis. Thyroid 19966 183-188.

30 Aksoy DY, Kerimoglu U, Okur H, Canpinar H, Karaagaoglu E, Yetgin S, Kansu E \& Gedik O. Effects of prophylactic thyroid hormone replacement in euthyroid Hashimoto's thyroiditis. Endocrine Journal 200552 337-343. (doi:10.1507/endocri.52.337)

31 Padberg S, Heller K, Usadel KH \& Schumm-Draeger PM. One-year prophylactic treatment of euthyroid Hashimoto's thyroiditis patients with levothyroxine: is there a benefit? Thyroid 200111 249-255. (doi: $10.1089 / 105072501750159651)$

32 Chiovato L, Vitti P, Lombardi A, Kohn LD \& Pinchera A. Expression of the microsomal antigen on the surface of continuously cultured rat thyroid cells is modulated by thyrotropin. Journal of Clinical Endocrinology \& Metabolism 198561 12-16.

33 Saicic ZS, Mijalkovic DN, Nikolic AL, Blagojevic DP \& Spasic MB Effect of thyroxine on antioxidant defense system in the liver of different aged rats. Physiological Research 200655 561-568.

34 Al-Rejaie SS, Aleisa AM, Sayed-Ahmed MM, Al-Shabanah OA, Abuohashish HM, Ahmed MM, Al-Hosaini KA \& Hafez MM. Protective effect of rutin on the antioxidant genes expression in hypercholestrolemic male Westar rat. BMC Complementary and Alternative Medicine 201313 136. (doi:10.1186/1472-6882-13-136)

Received 29 October 2015

Revised version received 22 February 2016

Accepted 7 March 2016 